\title{
Research on the Design and Application of Sports Competition Ticketing Platform Based on Edge Computing
}

\author{
Wenfeng Dai, ${ }^{1}$ Jiajia Shao, ${ }^{2}$ and Xiuli Zhang $\mathbb{D}^{3}$ \\ ${ }^{1}$ Sports Institute of Sanya University, Hainan, Sanya 572022, China \\ ${ }^{2}$ Department of Public Basic Education, Sanya Institute of Technology, Hainan, Sanya 572000, China \\ ${ }^{3}$ School of Physical Education, Zhengzhou University, Henan, Zhengzhou 450000, China \\ Correspondence should be addressed to Xiuli Zhang; zhangxiuli@zzu.edu.cn
}

Received 27 July 2021; Accepted 16 August 2021; Published 23 August 2021

Academic Editor: Huihua Chen

Copyright (C) 2021 Wenfeng Dai et al. This is an open access article distributed under the Creative Commons Attribution License, which permits unrestricted use, distribution, and reproduction in any medium, provided the original work is properly cited.

\begin{abstract}
Nowadays, under the encouragement of national and sports competition related policies, sports industry is gradually rising. In this case, how to provide ticketing services conveniently, quickly, and accurately for sports spectators all over the country and the world and how to keep up with the times and improve traditional ticketing services are two major problems that need to be solved urgently by those who are in charge of sports events. When investigating the current traditional ticketing platform for sports competitions, it is not difficult to find that most ticketing services rely heavily on manual services. From ticket purchase to ticket checking, consumers have poor experience, there is a lot of waste of manpower and material resources, and scalpers easily sell high-priced tickets. In addition, the traditional ticket sales mode still uses old-fashioned paper tickets or cards, which are difficult to preserve, making it difficult to prevent counterfeiting and use and control information statistics. Data confusion leads to financial risks. The "paralysis" of the ticketing system of many large-scale sports competitions, especially super-large sports competitions, just proves the importance and necessity of reforming ticketing platform of sports competitions in order to keep pace with development. This paper will study a large-scale (or super-large), flexible, efficient, and excellent performance, which can meet the burst peak access requirements of sports competition ticketing platform. We will first consider the overall demand of the sports competition ticketing market, then make a general analysis according to the demand, design a sports competition ticketing platform that can effectively serve large-scale or super-large sports competitions, and raise and solve the problems encountered when building the platform.
\end{abstract}

\section{Introduction}

In recent years, China's sports consumption market has a good development trend. At the same time, the network has an excellent development prospect. The emerging new technologies are changing people's lives, and the times are changing with each passing day. Since the successful conclusion of the 2008 Beijing Olympic Games, people have paid more and more attention to sports events, and they are more and more willing to pay attention to the consumption of sports-related industries. However, in fact, the online ticketing sales of sports competitions in China are not ideal, a considerable number of ticketing management methods are still offline, some ticketing system functions are incomplete, and defects abound. On the contrary, the online ticketing situation in the film industry is excellent, and most people are willing to buy tickets online, so it is necessary to make changes. Reference [1] introduces the concept of edge computing, compares edge computing with cloud computing, systematically analyzes and compares three representative edge computing platforms, lists typical applications, and describes advantages. Reference [2] discusses the differences between cloud computing and mobile edge computing (MEC) models. Reference [3] designs the data storage structure, the core program flow, and the initial parameters of the MySQL database management system, which laid a foundation for the development of the software system. Reference [4] uses cutting-edge technologies such as 
cloud computing technology to modernize, which can improve efficiency and reduce costs. It explains the service architecture of electronic booking system, the characteristics of the proposed system architecture, and the benefits of the proposed system. Reference [5] discloses a specific flow of a computing facility. Paper [6] describes the algorithm architecture and software and hardware codesign of digital edge computing layer based on Zynq platform under the background of Internet of Multimedia Things (IoMT). Reference [7] makes 5G Internet of Things applications access the edge computing platform, and analyzes the Internet of Things gateway. Reference [8] enables edge computing platforms to deliver rich Internet applications. Literature [9] combines blockchain technology with edge computing to establish a credible system and effectively utilizes some idle resources at the edge of the system. Reference [10] discusses several locations of system technologies and facilities on the cloud and evaluates the costs involved, so that the electronic ticketing system can reach a wide range of customers and run on the cloud. Reference [11] uses connection technology to adjust the dispatching and maintenance management system and finally implements closed-loop management for ticketing process. Reference [12] enables the system to have reading and writing performance and can be compared with the information of e-ticket, which can be applied to sports events held in various stadiums and gymnasiums. Reference [13] enables a user to establish contact with a ticketing system server through first and second digital data devices (e.g., a mobile phone, a PDA). Reference [14] provides a method for managing ticketing requests, receiving ticketing requests, allocating tickets to ticket purchasers, recording the bill request, receiving the bill request from the back-end office bill system, and delivering the bill to the purchaser. Reference [15] discloses a method of electronically converting a balanced viewer feed into an optimal recording balance value. Both ticket purchasers and non-ticket purchasers can connect to the Internet or wireless network through the retrieval system authenticated at the terminal equipment and automatically obtain interactive products related to recording or participating in events.

In the research structure of this paper, the second section explains the platform development theory, focusing on edge computing, cloud computing platform, and 5G communication technology. The third section explains the structure of ticketing system. The fourth section optimizes the platform by edge computing. Finally, the platform is tested and analyzed.

\section{Theoretical Basis of Platform Development}

2.1. Introduction to Edge Computing. Edge computing is not a brand new concept. This term first appeared in Ryan Ramosi's report in the United States in 2013. Researchers propose distributed edge computing to solve the delay and privacy protection problems of cloud computing. Edge computing can handle, analyze, and encrypt data; realize perception, control, and interaction among objects; ensure the security of data; and respond quickly to networked things. As shown in Figures 1 and 2, there are two normal forms.

Edge computing is a new computing paradigm that stores, calculates, and processes data between cloud and end users, close to end users.

Edge computing is divided into three layers of "terminaledge-cloud" model, and the logical structure is shown in Figure 3.

Figure 4 shows the edge computing reference architecture, including application domain, data domain, network domain, and equipment domain. It provides four kinds of software and hardware infrastructure: network, computing, storage, and application.

2.2. Cloudlet Computing Platform. Cloud computing platform is effectively compatible with various software and hardware facilities, making IT facilities easy to manage and control. Here, let us' take Cloudlet as a typical representative as shown in Figure 5.

Cloud computing has complete computing and storage capabilities and can directly enter the cloud through mobile devices. Its architecture diagram is shown in Figure 6.

Choose the best edge computing platform according to different demand scales, and we can refer to Table 1 to give a reasonable choice.

2.3. 5G Communication Technology. 5G communication technology has many advantages such as higher speed and low delay. What is superior in the $5 \mathrm{G}$ era is that $4 \mathrm{G}$ is always limited by factors such as network speed and delay, and it also limits the development of other technologies. In the $5 \mathrm{G}$ era, it will be a new node, and the whole world will be connected by the network, not just virtual contact on the Internet, people, things and things, and people and things. 5G network supports a variety of Internet of Things devices, which can help terminals reduce end-to-end network latency by $30 \%$, and can rationally utilize various effective resources, such as edge computing resources and cloud computing resources.

\section{Architecture Design of Ticketing Platform}

\subsection{Basic Requirements Analysis}

(1) Provide a variety of ticket purchase channels

(2) Provide real-time and accurate ticketing inquiry and sales

(3) Provide ticketing processing capability that can meet sudden large-scale visits

(4) Provide anti-counterfeiting and easy-to-preserve tickets

(5) Provide accurate data, which is safe, reliable, and easy to use and control 


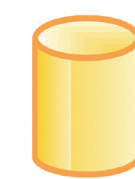

Data Producer

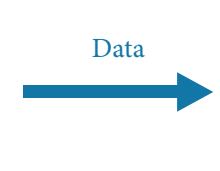

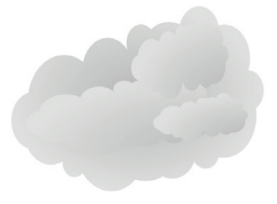
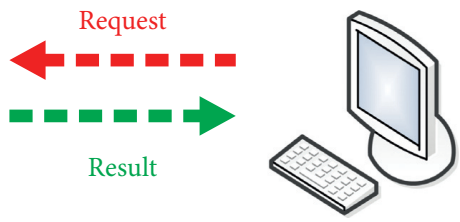

Data Consumer

FIgURe 1: Cloud computing paradigm.

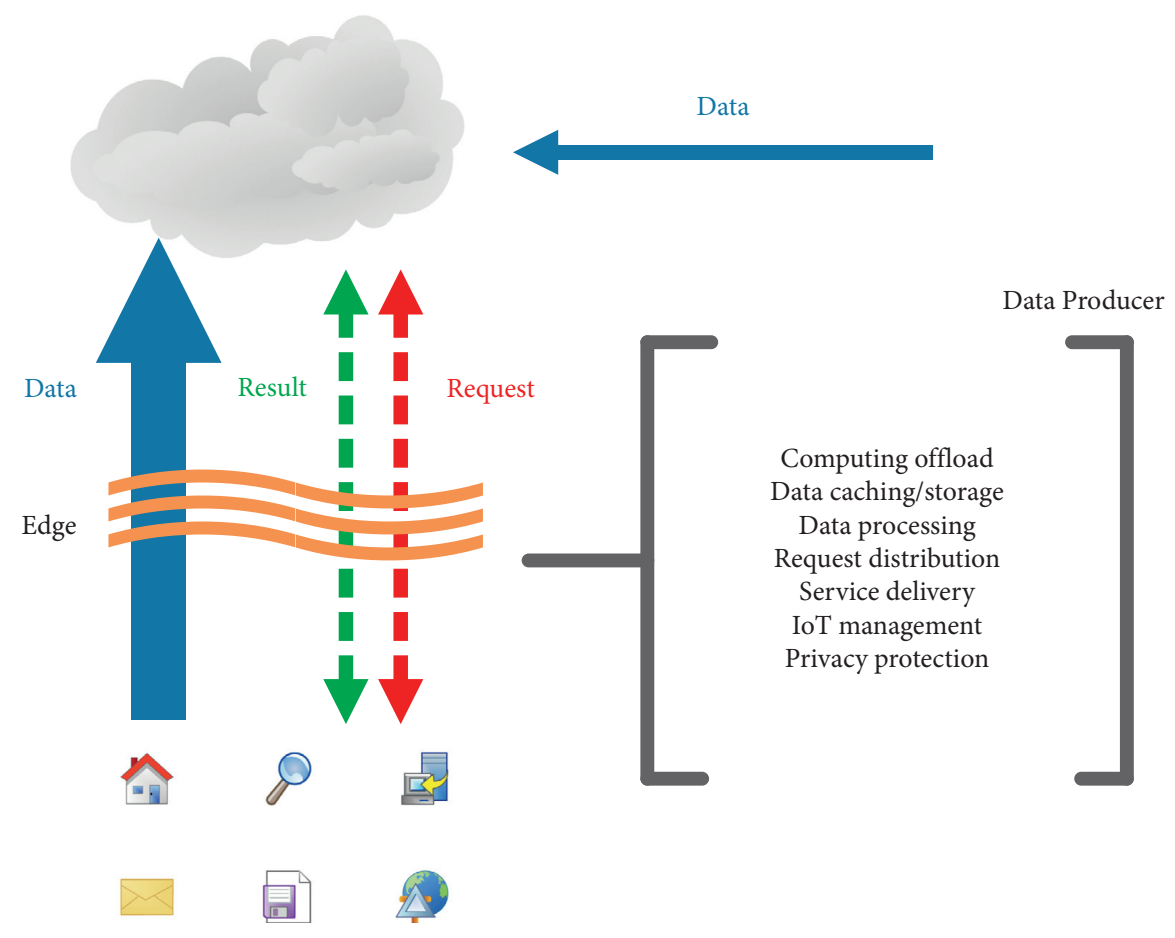

Data Producer/Consumer

FIGURE 2: Edge computing normal form.
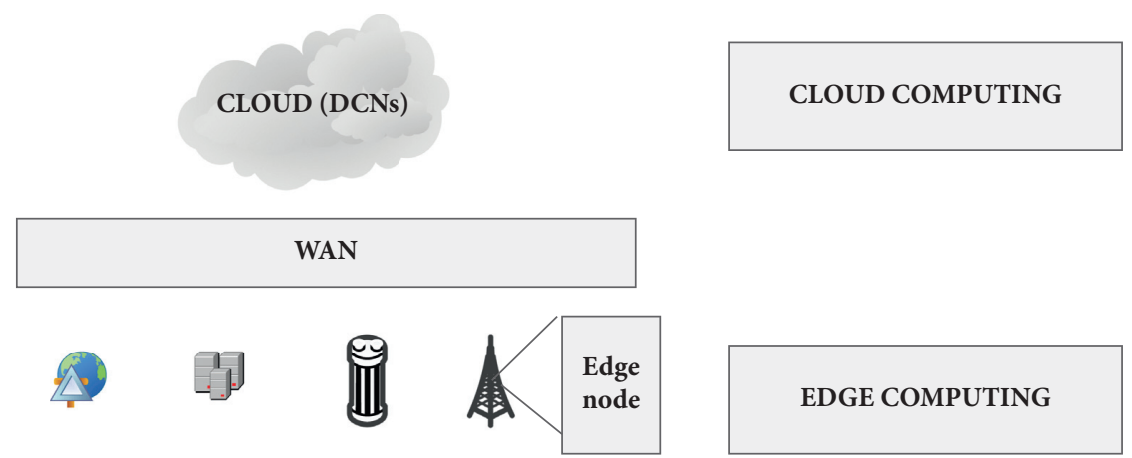

Wi-Fi, Bluetooth, Cellular, ZigBee, Local Network

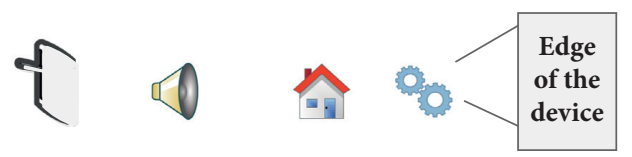

END DEVICES

FIgURE 3: Logical structure diagram of edge calculation. 


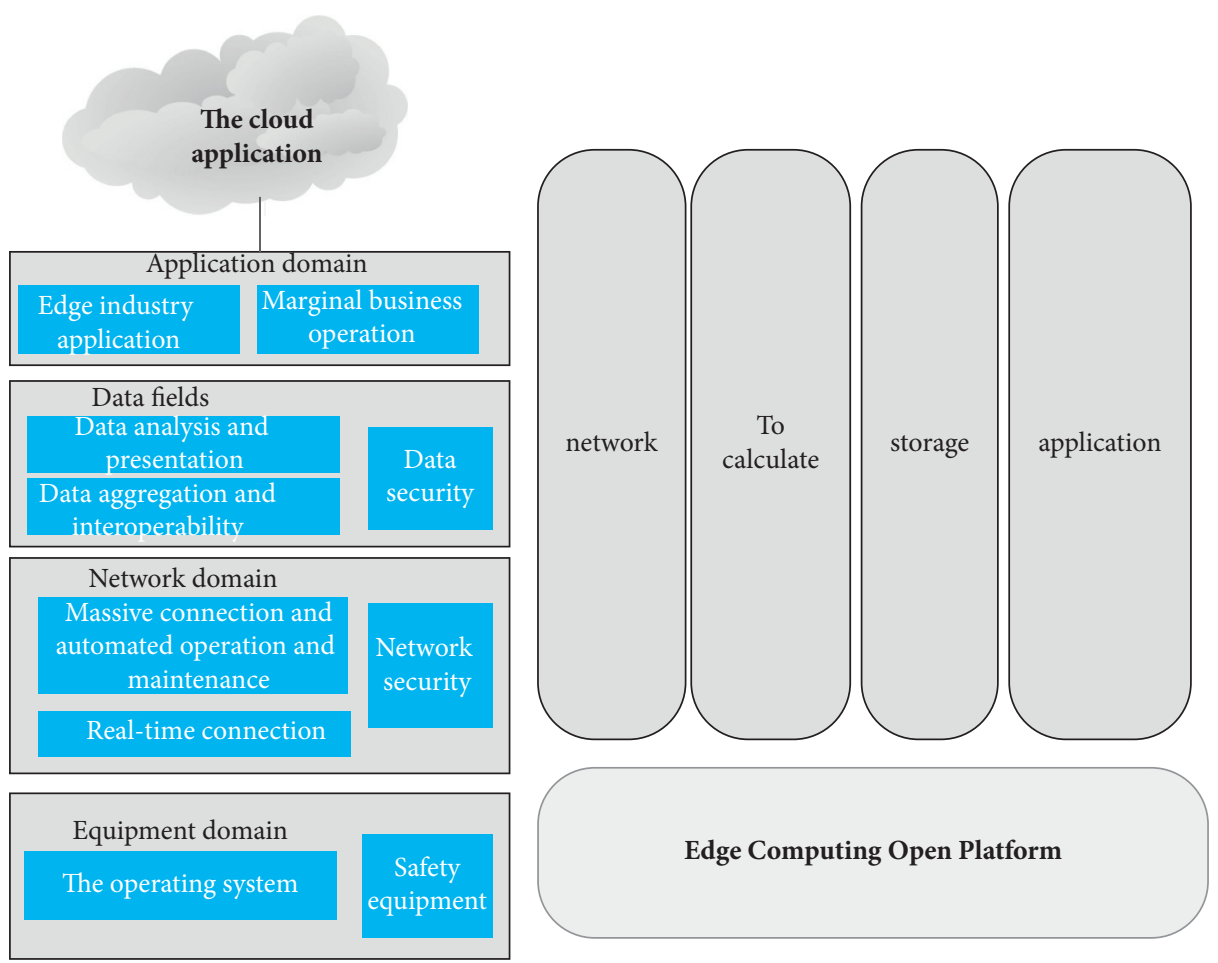

FIGURE 4: Edge computing reference architecture.

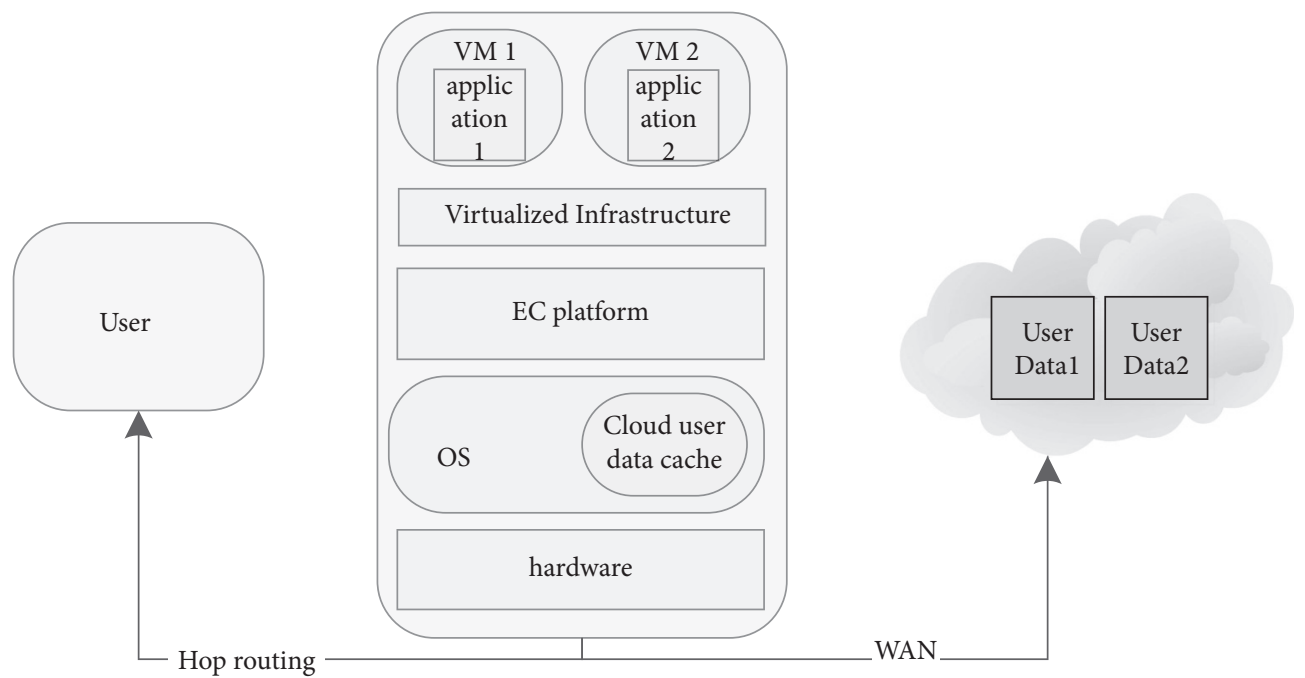

FIGURE 5: Cloudlet computing platform structure diagram.

(6) Provide a series of efficient ticketing services without waiting

Ensure the advanced technology of the platform in a short time. Ensure that the platform has a clear division of labor and develops functions according to modules. The above puts forward six main contents that need to be analyzed, and the edge computing technology proposed in this paper needs to calculate the main requirements of real-time and accurate ticketing inquiry and sales, anti-counterfeiting and easy-to-save ticketing, accurate data, safety and reliability, and ease of use and control, so as to improve the comprehensive performance of the platform.

3.2. Infrastructure Design. As shown in Figures 7 and 8, the ticketing platform architecture of sports competition forms an interlocking and closely related ticketing platform architecture.

In Figure 7, data needs to be processed in the core system; for example, data sharing, data exchange, data mining, and other modules need to be realized through edge computing. It can improve the performance of application services and the satisfaction of clients. 


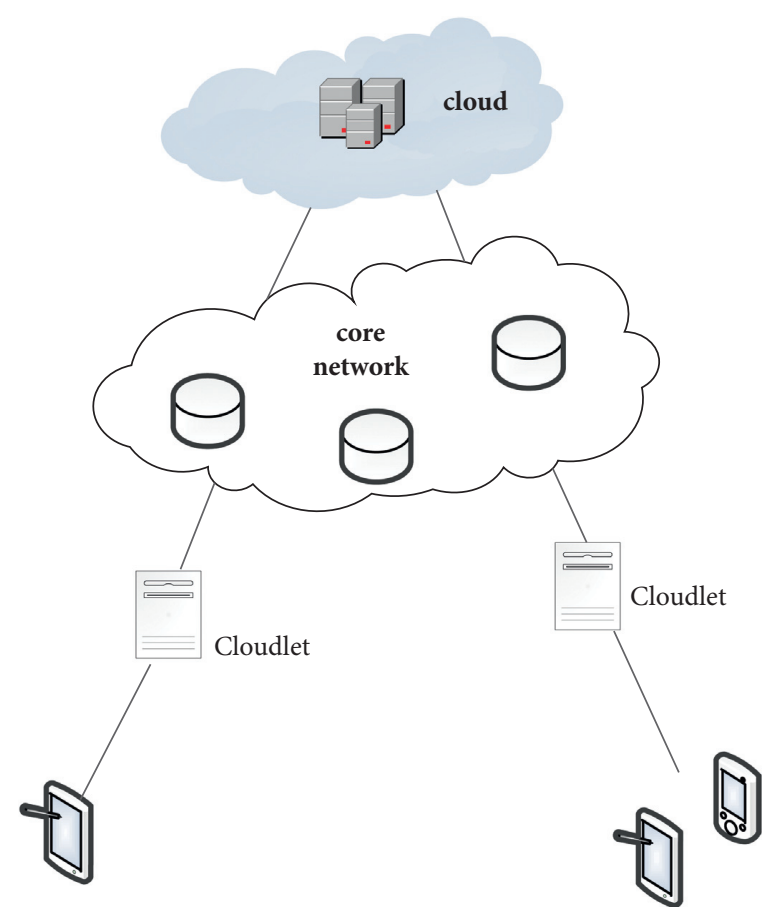

FIGURE 6: Cloudlet architecture diagram.

TABle 1: Comparison table of edge computing platforms.

\begin{tabular}{|c|c|c|c|c|}
\hline Platform & $\begin{array}{l}\text { Moving edge } \\
\text { computing }\end{array}$ & Fog calculation & EdgeX Foundry & Cloud computing \\
\hline Node equipment & Server & Router, gateway, etc. & $\begin{array}{l}\text { Customized devices, routers, } \\
\text { gateways, switches }\end{array}$ & $\begin{array}{l}\text { Micro data center, } \\
\text { cluster }\end{array}$ \\
\hline Node position & $\begin{array}{l}\text { Wireless controller/ } \\
\text { base station }\end{array}$ & $\begin{array}{l}\text { Terminal device to any } \\
\text { device in the cloud }\end{array}$ & $\begin{array}{l}\text { Mainly located at network } \\
\text { access points }\end{array}$ & $\begin{array}{c}\text { Located at the network } \\
\text { access point }\end{array}$ \\
\hline $\begin{array}{l}\text { Environment perception } \\
\text { ability }\end{array}$ & High & Medium & Medium & Low \\
\hline Proximity degree & A jump & One or more jumps & A jump & A jump \\
\hline Access mode & Cellular network & $\begin{array}{c}\text { Bluetooth, WiFi, cellular } \\
\text { network }\end{array}$ & $\begin{array}{c}\text { Bluetooth, WiFi, cellular } \\
\text { network }\end{array}$ & WiFi \\
\hline Energy consumption & High & Low & Low & Low \\
\hline Calculation delay & Low & High & Low & Low \\
\hline $\begin{array}{l}\text { Deployment, operation, and } \\
\text { maintenance }\end{array}$ & General & General & Simple & General \\
\hline
\end{tabular}

3.3. Calculation Implementation. The ticketing system calculates and implements specific procedures for (1) receiving orders for ticketing services transmitted to the facility through a remote input device, (2) determining whether the ticketing system has ordered services, (3) sending a notice of unavailability to the remote input device if the ticketing service cannot meet the requirements of the order, and (4) completing the order and putting it on record if the ticketing service is sufficient to meet the order, as shown in Figure 9.

3.4. Ticketing Platform Core. The web server, which handles millions of web requests per hour, is the core of the sports ticketing platform we designed. It stores the website in an Internet data center as a web server for ASP/JSP.
Application environments such as NET/PHP can be deployed as needed.

As shown in Figure 10, we divide the functions of website servers, and the number of servers for each function varies, which may be several or hundreds.

\section{Research on Optimization of 4 Platforms}

4.1. Optimizing Edge Computing System. For the hardware description of chaos generator, simple chaotic generators such as Henon and Skew Tent maps are used, which greatly improves the encryption efficiency and reduces the limitation of hardware to edge computing system.

(1) Henon map is a discrete-time dynamic system that can produce chaotic phenomena. The definition is as follows: 


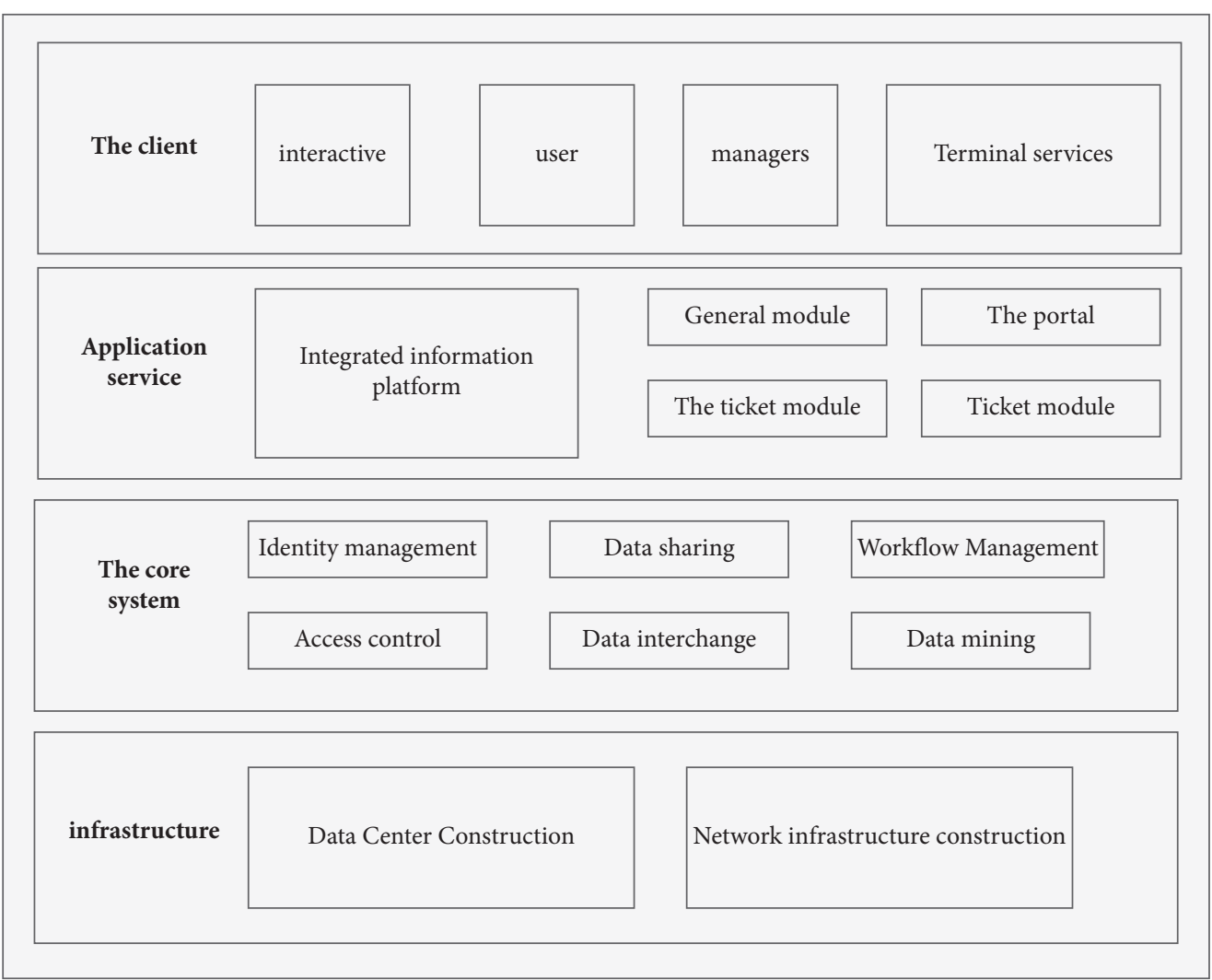

FIGURE 7: Logical architecture of ticketing platform.

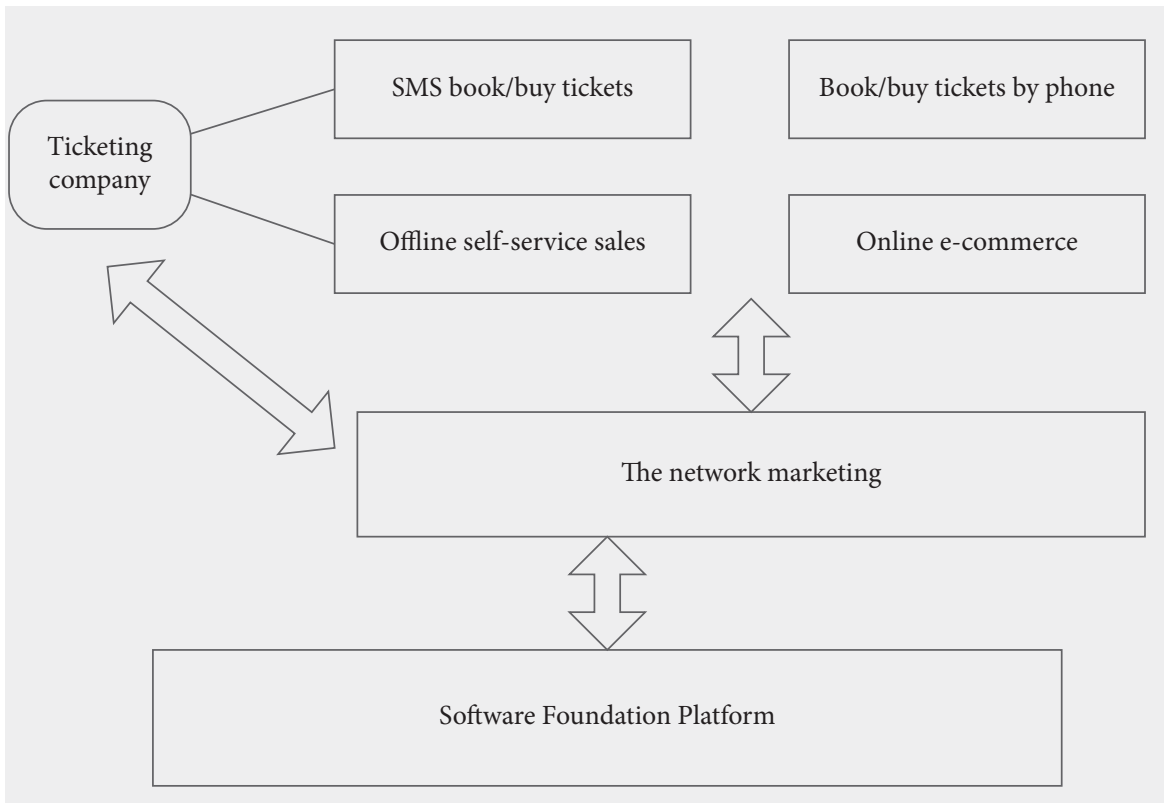

FIgURE 8: Ticketing platform architecture.

$$
\begin{aligned}
& x_{n+1}=1+y_{n}-a \cdot x_{n}^{2}, \\
& y_{n+1}=b \cdot x_{n},
\end{aligned}
$$

where $a$ and $b$ are the bifurcation parameters of the mapping and $x_{0}$ and $y_{0}$ are the initial conditions. The traditional approach is to use $x_{0}=y_{0}=0$. In order to realize chaotic behavior, $a$ and $b$ are often equal to 1.4 and 0.3 , respectively. As mentioned earlier, for this work, we used $b=0.3$, and a is a constant, depending on the content of the input image. 


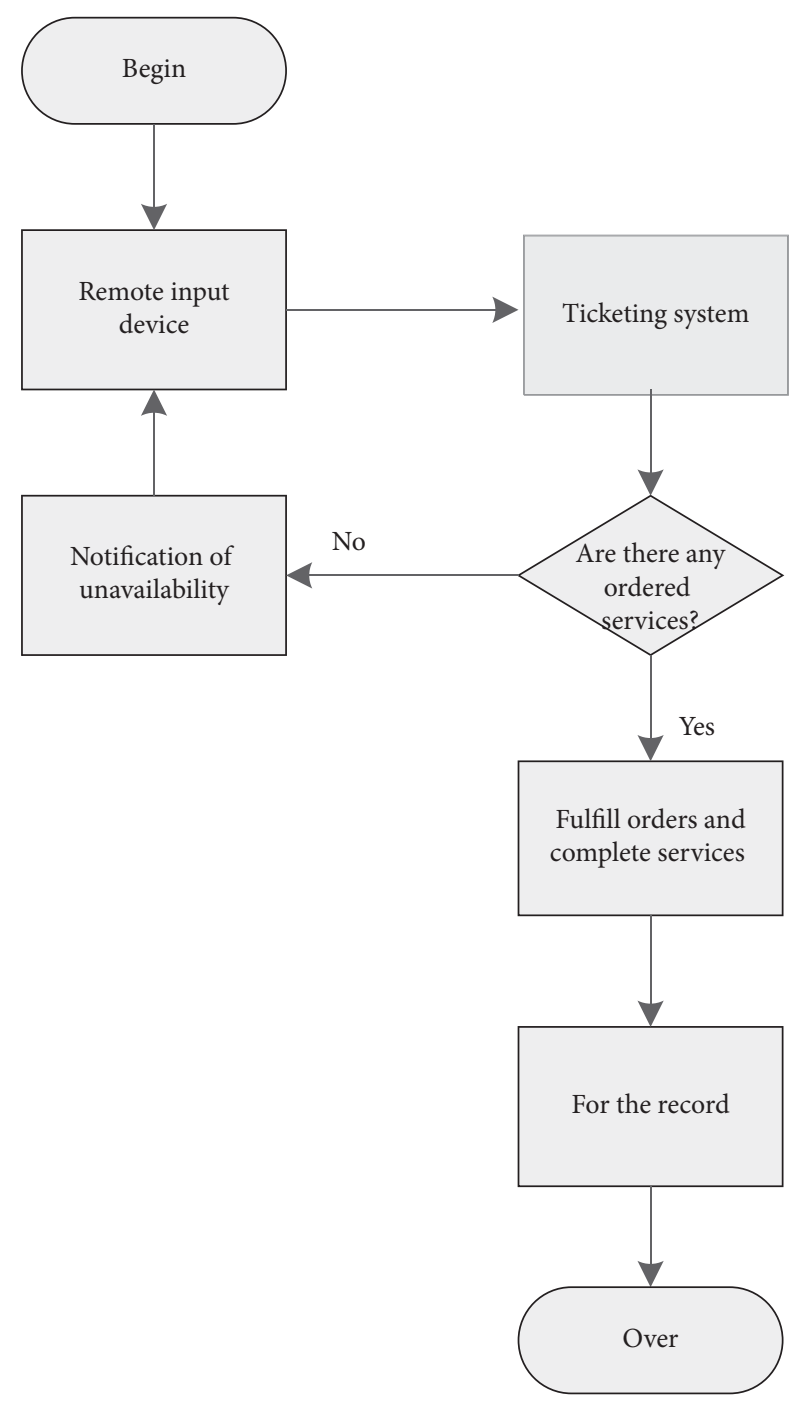

Figure 9: Specific flow of ticketing system calculation and implementation.

(2) Skew Tent, also known as 1D asymmetric tent mapping, is used in many encryption schemes because of its simplicity, large key space, and high sensitivity. Its mapping is defined as follows:

$$
S_{n+1}= \begin{cases}\frac{S_{n}}{p}, & \text { if } S_{n} \epsilon[0, p], \\ \left(1-S_{n}\right)(1-p), & \text { if } S_{n} \epsilon(p, 1],\end{cases}
$$

where $S_{n} \in[0,1]$ is the system state and $p \in(0,1)$ is the control parameter. Initial conditions $S_{0}$ and $p$ can be used as keys. In this job, $p$ is fixed at 0.54321 . The signal flow graph (SFG) of the Henon and Skew Tent diagrams is shown in Figure 11.

As shown in Figure 11, the proposed chaos generator architecture can be obtained using simple logical and arithmetic operators and is suitable for hardware implementation. Four HW/SW partition-based configurations address trade-offs between execution time, region, and

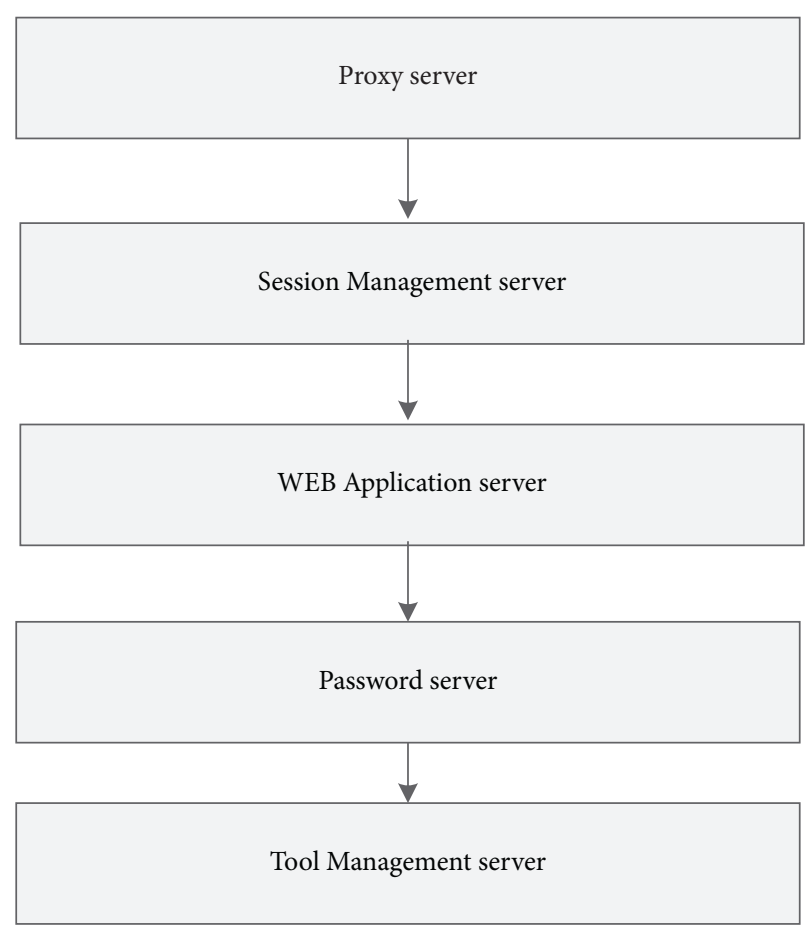

FIGURE 10: Function partition diagram of website server.

energy consumption. In the experiment, more components are moved to hardware for execution, which can achieve more than 9 times timing acceleration and improve power efficiency by 7.7 times with almost no energy consumption.

4.2. Optimizing the Utilization of Idle Resources in the System. DETEC combines cluster chain technology with load calculation and constructs a trust system for calculating each participant, which gets a reward. A heuristic algorithm is used to solve a task allocation problem considering both node capacity and reward fairness. Finally, a police patrol model is used to optimize the overall reward of the system to ensure the credibility of the calculation results.

4.3. Optimizing Seamless Offline/Online Handover. When the passenger flow is heavy, the ticketing platform for sports competitions should have a smooth operating system to avoid unexpected situations such as jamming and crash. It is not enough to optimize the computational efficiency, but we should make some necessary adjustments from the details. When the platform is used, it must have the superior performance of uninterrupted work, which can realize seamless switching between offline and online handover and truly achieve super-smooth use effect.

There are two ways to solve this optimization problem: one is data-centric technology, and the other is serviceoriented technology, as shown in Figure 12.

4.4. Optimizing Intelligent Updates. In the past, the traditional client deployment and update were very complex. Although real-time network connection is not needed, the 


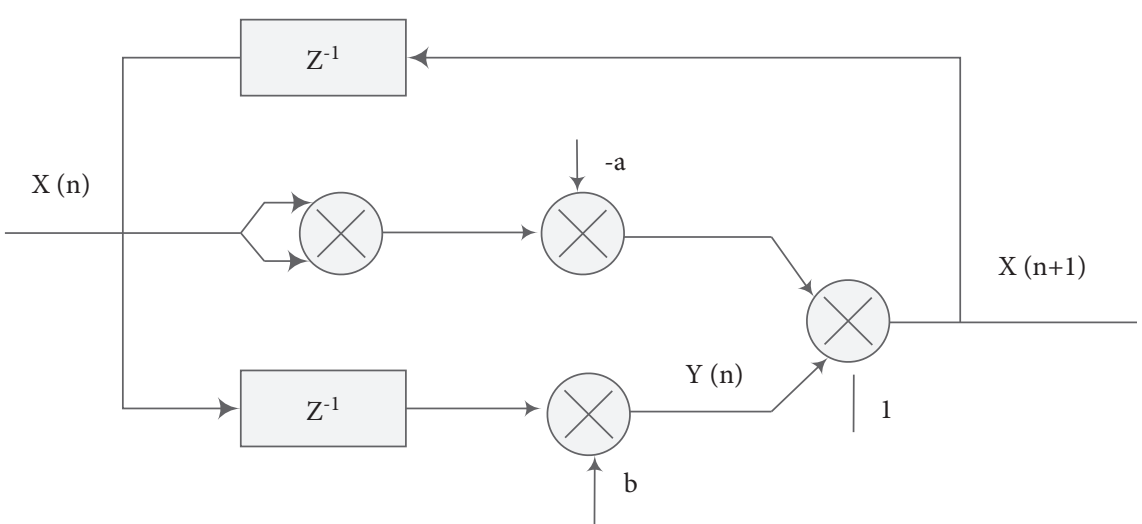

(a)

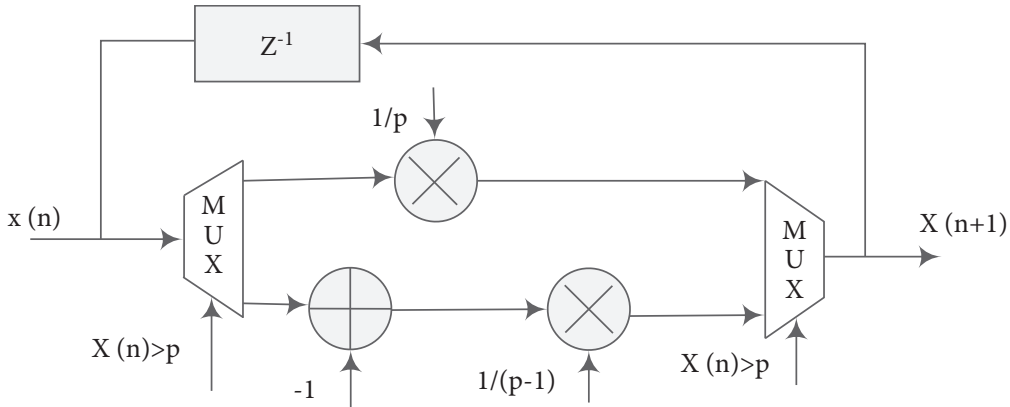

(b)

FIgURE 11: SFG diagram: (a) Henon map; (b) Skew Tent map.

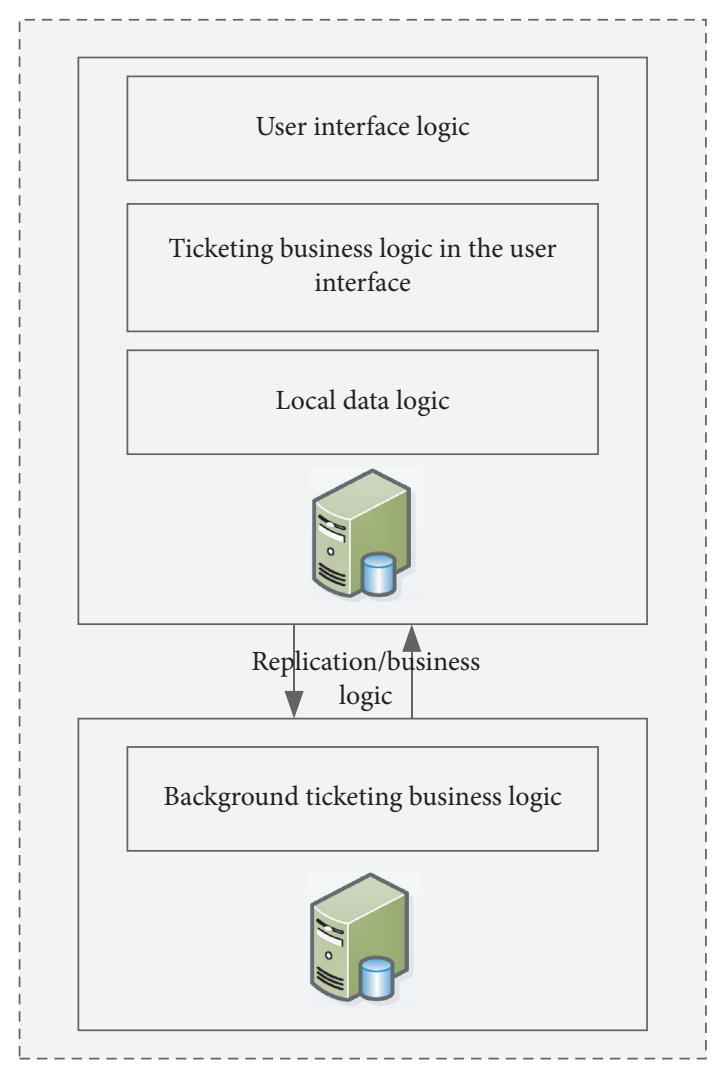

(a)

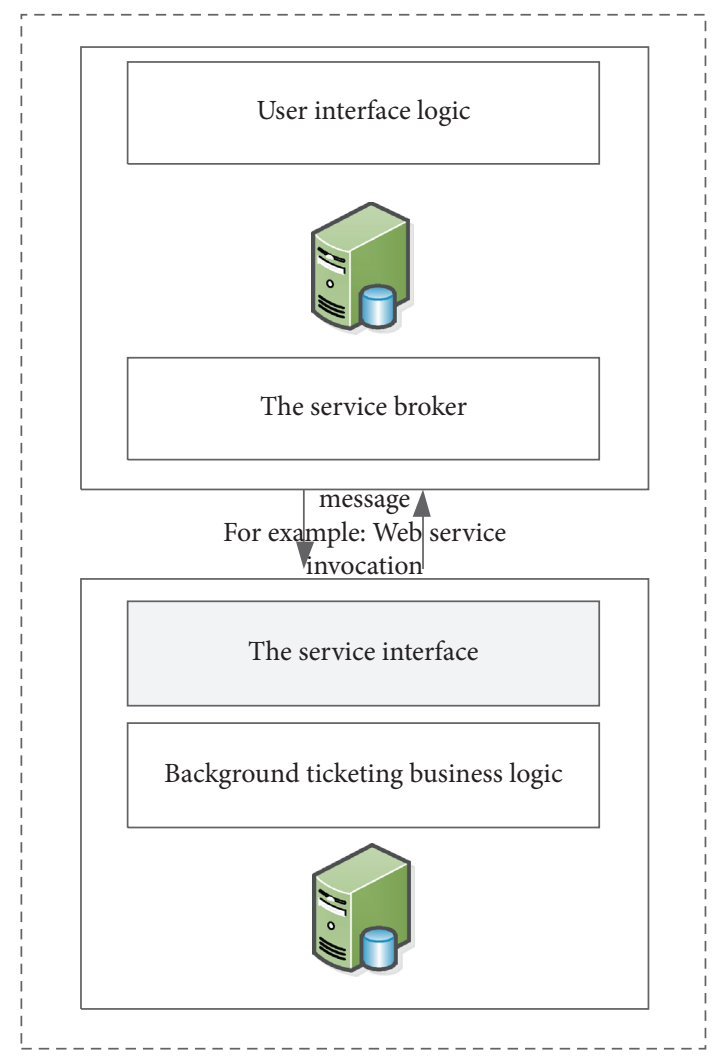

(b)

Figure 12: Architecture diagram of two technologies: (a) data-centric technologies; (b) service-oriented technologies. 
TABLE 2: Update methods for smart client applications.

\begin{tabular}{|c|c|c|c|c|c|}
\hline & $\begin{array}{c}\text { Contactless } \\
\text { deployment } \\
\text { update }\end{array}$ & $\begin{array}{l}\text { Automatic update with } \\
\text { application update stub }\end{array}$ & $\begin{array}{l}\text { Getting } \\
\text { updates from a } \\
\text { file share } \\
\end{array}$ & $\begin{array}{l}\text { Xcopy } \\
\text { update }\end{array}$ & Windows setup update \\
\hline Non-superuser updates & Yes & $\begin{array}{l}\text { Depending on the } \\
\text { requirements of the } \\
\text { application }\end{array}$ & Yes & No & $\begin{array}{l}\text { Depending on the requirements of } \\
\text { the application and the application } \\
\text { distribution mechanism }\end{array}$ \\
\hline $\begin{array}{l}\text { Centralized update } \\
\text { management }\end{array}$ & Yes & Yes & Yes & No & $\begin{array}{l}\text { Depending on the application } \\
\text { distribution mechanism }\end{array}$ \\
\hline $\begin{array}{l}\text { Downloading updates } \\
\text { when running the } \\
\text { application }\end{array}$ & Yes & Yes & No & No & 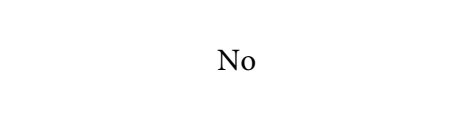 \\
\hline $\begin{array}{l}\text { Federated update } \\
\text { infrastructure }\end{array}$ & No & Yes & No & No & Yes \\
\hline $\begin{array}{l}\text { Update on a user/group- } \\
\text { by-user basis }\end{array}$ & Yes & Yes & No & No & $\begin{array}{l}\text { Depending on the application } \\
\text { distribution mechanism }\end{array}$ \\
\hline Transactional update & No & Yes & No & No & Yes \\
\hline $\begin{array}{l}\text { Built-in version control } \\
\text { support }\end{array}$ & No & No & No & No & Yes \\
\hline
\end{tabular}

Note. "Automatic update with application update stub" is the most efficient and best way to deploy platform updates in modern client application update technologies.

response is not fast enough, and some small problems of unstable operation often occur when using it, which need to be reported and summarized from time to time. When designing the sports ticketing platform, we seriously considered how to design smart client applications. We used the existing technology to minimize the impact of deployment and update, reduce the burden on the system, and clean up unnecessary and cumbersome data. We will use different mechanisms to choose the best way to update the application and ticketing business rules in different scenarios.

The method for deploying updates is shown in Table 2.

4.5. Optimizing Resources through Caching Technology. When we develop high-performance and high-availability applications, caching technology can help us achieve this requirement, save resources, and achieve optimization. We will keep the domain name resolution and the ticketing resource object itself (such as ticketing information, announcements, notifications) which has been accessed, and it is very likely that they will be used again in the future. This can reduce the waste or consumption of system resources and network resources to a certain extent.

\section{Platform Function Test and Analysis}

In the ticketing platform of sports competition, inquiring, booking, and purchasing tickets are the core basic functions, and they are also the most important contents when we test and analyze the platform functions. We aim to test the various performance aspects of the platform, so as to find problems, solve them, and continuously improve the details. A professional testing tool is used to test the network ticketing system and simulate whether the system functions can meet the needs smoothly under the condition of sudden and large number of visits.
TABLE 3: Interface operation test.

\begin{tabular}{lcc}
\hline Number & Test content & $\begin{array}{c}\text { Test } \\
\text { results }\end{array}$ \\
\hline 1 & Home navigation position & Normal \\
2 & Navigation bar content layout interface layout & Normal \\
3 & Interface layout & Normal \\
4 & Text display & Normal \\
5 & Font size & Normal \\
6 & Garbled code & None \\
7 & Hyperlink & Normal \\
\hline
\end{tabular}

5.1. UI Testing. Through Google Chrome browser manual operation identification detection, we test platform operation interface rationality. The test results are shown in Table 3.

In the test in Table 3, the interface can meet the basic requirements of a system. After passing the test, the system can run normally, and further interface test is needed in the later performance method. The system also needs long-term operation and maintenance, upgrade, etc. This will improve the user experience of the system and meet the experience of different customers.

5.2. User Service Performance Testing. The test passing criteria are shown in Table 4.

5.3. Compatibility Testing. Test cases and test results are shown in Table 5.

5.4. System Response Time Index. Response time refers to the time taken to execute a request or task. Before the formal test, focus on $100 \mathrm{~ms}$ as the upper limit of response time. First, use an example to make simple statistics. Figures 13 and 14 show the statistics and distribution of response time. 
TABLE 4: Server performance test passing criteria.

\begin{tabular}{lccc}
\hline Category & Judgment dimension & Not passing & Passing \\
\hline & Timeout probability & More than one ten thousandth & Less than one ten thousandth \\
& Error probability & More than one ten thousandth & Less than one ten thousandth \\
TPS & Less than the expected peak value & Greater than the expected peak value \\
$\begin{array}{l}\text { Server-side } \\
\text { performance }\end{array}$ & TPS fluctuation range & Less than $8 \%$ & More than $8 \%$ \\
& CPU utilization & More than $75 \%$ & Less than $75 \%$ \\
& Load & Average CPU load per core: greater than 1 & Average load per CPU core: less than 1 \\
& JVM memory usage & More than 80\% & Less than 80\% \\
Full GC frequency & On average, less than once every half hour & On average, more than once every half hour \\
\hline
\end{tabular}

Table 5: Compatibility test cases and results.

\begin{tabular}{lrlr}
\hline Number & Test case & Test \\
\hline 1 & It can be installed and enabled normally on different platforms, without card machine or flashback phenomenon. & Pass \\
2 & Login, page browsing, search, comment and other interfaces have no deformation, occlusion, uncoordinated size, and & Pass \\
other problems and can be scaled and displayed at different resolutions. & Pass \\
3 & Verify that interactive controls such as text boxes and keys in the interface can click and respond normally. & Pass \\
4 & The table/list control in the verification interface can load network content, and the icon and text of a single table item/ & Pass \\
5 & Verify that the font and resolution in the interface are scaled to a certain extent. & Pave no distortion and occlusion. \\
\hline
\end{tabular}

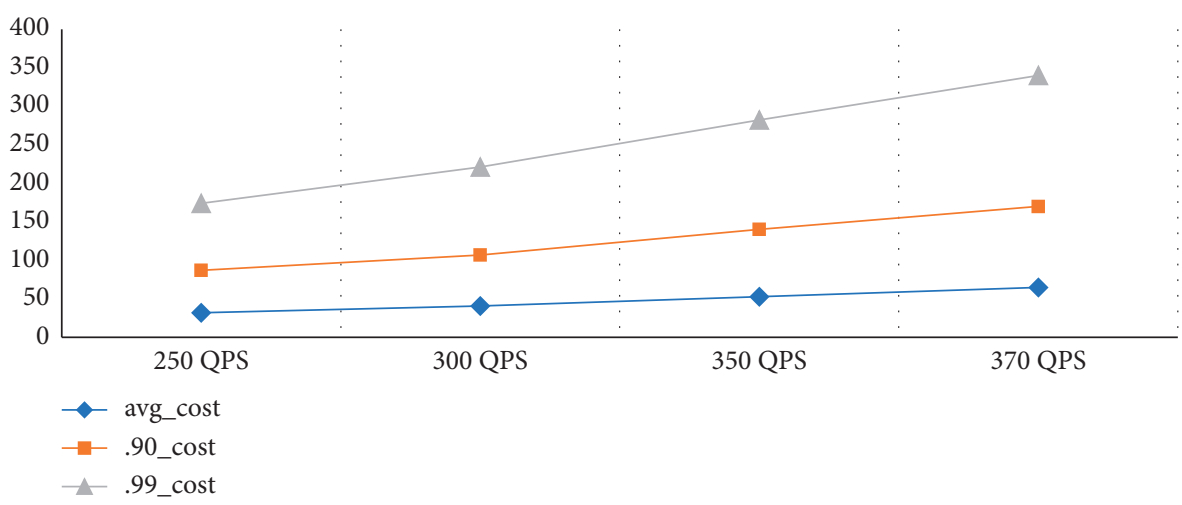

FIgURE 13: Response time statistics.

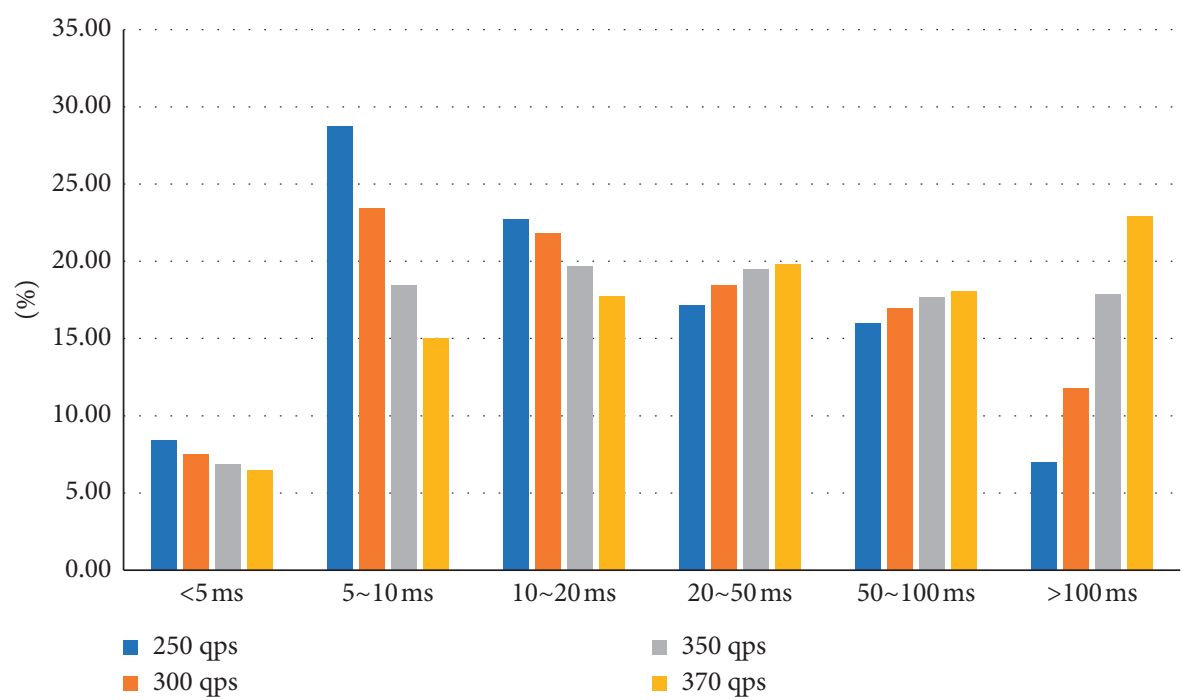

FIgURE 14: Response time distribution. 
TABle 6: System query test results.

\begin{tabular}{|c|c|c|c|c|c|c|c|c|}
\hline & Number of concurrent information query requests & 1000 & 2000 & 3000 & 4000 & 5000 & 6000 & 7000 \\
\hline \multirow{2}{*}{ This system } & Average response time per request $(\mathrm{ms})$ & 23 & 50 & 112 & 197 & 349 & 583 & 726 \\
\hline & Transaction success rate $(\%)$ & 100 & 100 & 100 & 100 & 100 & 100 & 100 \\
\hline \multirow{2}{*}{ Ticket pass ticketing system } & Average response time per request & 24 & 70 & 148 & 257 & 467 & 828 & 1501 \\
\hline & Transaction success rate $(\%)$ & 100 & 100 & 100 & 100 & 100 & 100 & 100 \\
\hline
\end{tabular}

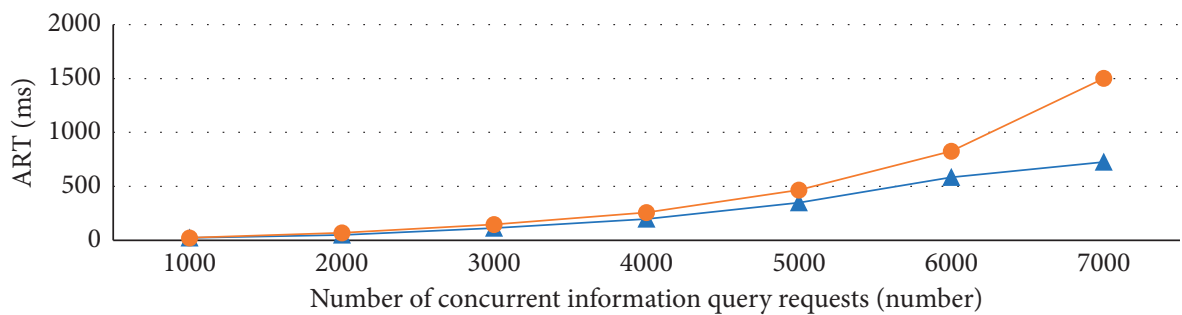

- Average response time per request of the system (ms)

- - Average response time per request of the ticketing system (ms)

FIGURE 15: ART-concurrent information query request curve.

TABLE 7: Test results of ticket transaction processing function.

\begin{tabular}{|c|c|c|c|c|c|c|c|c|}
\hline & Transaction volume of concurrent tickets & 30 & 60 & 90 & 120 & 150 & 180 & 200 \\
\hline \multirow{2}{*}{ This system } & Average response time per request (ms) & 77 & 154 & 235 & 357 & 507 & 665 & 821 \\
\hline & Transaction success rate $(\%)$ & 100 & 100 & 100 & 100 & 100 & 100 & 100 \\
\hline \multirow{2}{*}{ Ticket pass ticketing system } & Average response time per request (ms) & 80 & 168 & 280 & 409 & 598 & 987 & 1501 \\
\hline & Transaction success rate $(\%)$ & 100 & 100 & 100 & 100 & 100 & 100 & 100 \\
\hline
\end{tabular}

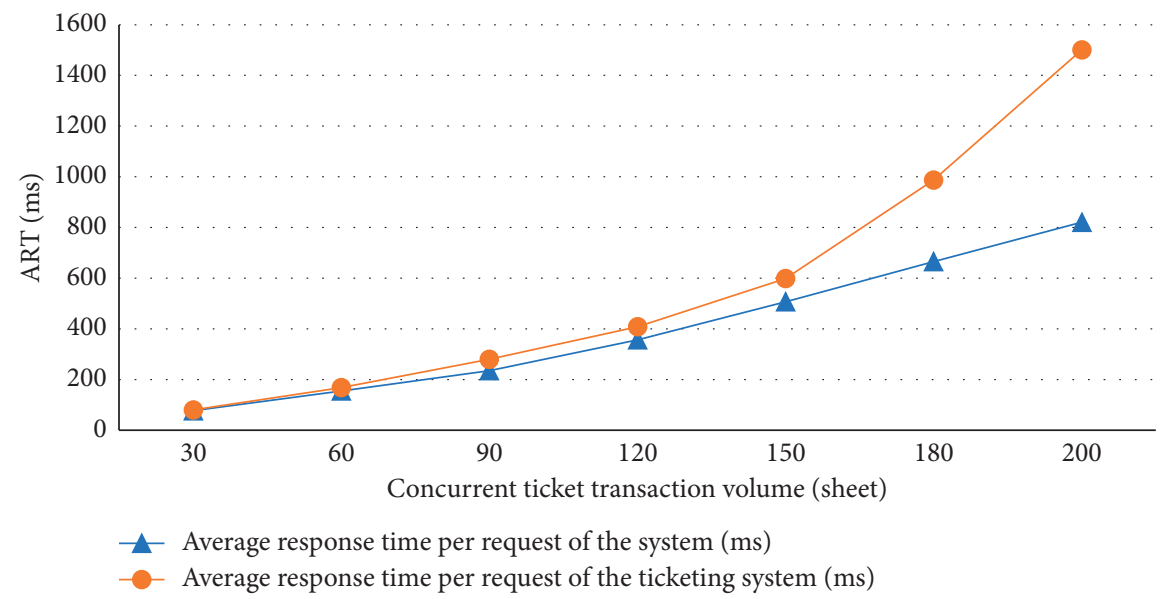

FIgURE 16: ART-concurrent completion ticket volume curve.

5.5. Two Specific Functional Tests. The functional tests are as follows:

\section{ART: average response time per request}

TPS: for the number of concurrent requests that can be responded to per second

The influence of ART and TPS indexes on the load performance of ticketing system can be determined. Because it is a simulation system, we consider many factors, such as cost, time, and experimental conditions. According to past experience, we reduce the system to an equal scale, which is convenient for the experiment.
5.5.1. Query Function Test. According to the number of query requests, there are seven groups: 1000, 2000, 3000, 4000, 5000, 6000, and 6500. The data are shown in Table 6 and Figure 15.

5.5.2. Ticket Transaction Processing Function Test. According to the concurrent requirements, the ticket transaction volume is divided into seven groups: 30, 60, 90, 120, 150, 180, and 200. The data are shown in Table 7 and Figure 16.

5.5.3. Analysis of Test Results. According to the experimental results in Sections 5.5.1 and 5.5.2, our analysis is as follows: 
When 6000 people make ticketing inquiries at the same time, the average response time of the system is $583 \mathrm{~ms}$, and the success rate is $100 \%$. At this time, the system also has a certain load space.

When the system carries out 180 ticket transactions at the same time, the average response time of the system is $665 \mathrm{~ms}$, the success rate is $100 \%$, and there are remaining tickets.

\section{Conclusion}

To sum up, the design and application of sports competition ticketing platform based on edge computing proposed in this study are reasonable and meet the overall needs of the current ticketing market according to edge computing, cloud computing platform, and 5G communication technology. The computing system in this study has higher efficiency and more obvious advantages. However, when we tested and analyzed the platform function, we did not 'test it in a real environment but only reduced the system to simulate the test. Therefore, our experimental results and conclusions still need to be revised and refined.

\section{Data Availability}

The experimental data used to support the findings of this study are available from the corresponding author upon request.

\section{Conflicts of Interest}

The authors declare that they have no conflicts of interest regarding this work.

\section{Acknowledgments}

This work was supported in part by Hainan Philosophy and Social Science Planning Project (HNSK(YB)19-56 and 2019BTY004).

\section{References}

[1] Z. Zhao, F. Liu, Z. Cai et al., "Edge computing: platforms, applications and challenges," Journal of Computer Research and Development, vol. 55, no. 2, pp. 327-337, 2018.

[2] I. Hussain, Q. Duan, and T. Zhong, "Service performance tests on the mobile edge computing platform: challenges and opportunities," Smart Service Systems, Operations Management, and Analytics, pp. 241-253, 2020.

[3] A. Andersons and S. Ritter, "Advanced RFID applications for sports events management: the case of SPORTident in Latvia," Procedia Computer Science, vol. 43, no. 3, pp. 78-85, 2015.

[4] N. Abdul Hamid, M. F. Al A'zhim, and M. L. Yap, "e-ticzketing system for football events in Malaysia," in Proceedings of the International Conference for Internet Technology and Secured Transactions, pp. 556-561, London, UK, December 2012.

[5] R. Mendes Lübeck, M. L. Wittmann, and L. Flores Battistella, "Electronic ticketing system as a process of innovation," Journal of Technology Management \& Innovation, vol. 7, no. 1, pp. 17-30, 2012.
[6] J. Maher, C. Thibault, D. Victor et al., "SoC-based edge computing gateway in the context of the Internet of multimedia things: experimental platform," Journal of Low Power Electronics and Applications, vol. 8, no. 1, pp. 1-10, 2018.

[7] H.-C. Hsieh, J.-L. Chen, and A. Benslimane, "5G virtualized multi-access edge computing platform for IoT applications," Journal of Network and Computer Applications, vol. 115, no. 8, pp. 94-102, 2018.

[8] A. Jolfaei, P. Ostovari, M. Alazab, I. Gondal, and K. Kant, "Guest editorial special issue on privacy and security in distributed edge computing and evolving IoT," IEEE Internet of Things Journal, vol. 7, no. 4, pp. 2496-2500, 2020.

[9] L. Cui, S. Yang, Z. Chen, Y. Pan, Z. Ming, and M. Xu, "A decentralized and trusted edge computing platform for Internet of things," IEEE Internet of Things Journal, vol. 7, no. 5, pp. 3910-3922, 2020.

[10] F. Araujo, M. Curado, P. Furtado, and R. Barbosa, “Taking an electronic ticketing system to the cloud: design and discussion," in Proceedings of the IEEE International Conference on Big Data (Big Data), pp. 1-10, Washington, NJ, USA, October 2014.

[11] B. K. Ng and Z. A. Akasah, "Maintenance management system for industrialized building system," in Proceedings of the International Building \& Infrastructure Technology Conference, Penang, Malaysia, June 2011.

[12] J.-lin Han and X. Wang, "Research of RFID ticket management information system for sports events. Science and engineering research center," in Proceedings of 2015 International Conference on Materials Engineering and Industrial Applications (MEIA 2015), pp. 308-310, Guilin, China, March 2015.

[13] L. S. Rogel and J. J. Ossenmacher, "Digital ticket issuance, exchange and validation systems and methods," US20130159026, 2013.

[14] T. H. Benson, B. E. Michalak, and M. S. Duffy, "Computer implemented method for managing electronic ticket requests," US20100312587, 2010.

[15] A. R. Gurvey, "Electronic system and method coupling live event ticketing and interactive entries with the sale, distribution and transmission of event recordings, mastering system and intelligent terminal designs," US2006017370, 2006. 